\title{
Targeting 20-HETE producing enzymes in cancer - rationale, pharmacology, and clinical potential
}

This article was published in the following Dove Press journal:

OncoTargets and Therapy

25 March 2013

Number of times this article has been viewed

\author{
Anna Alexanian \\ Andrey Sorokin \\ Department of Medicine, Medical \\ College of Wisconsin, Milwaukee, \\ WI, USA
}

Correspondence: Andrey Sorokin Department of Medicine, Medical College of Wisconsin, 870I Watertown Plank Road, Milwaukee, WI 53226, USA

Tel + I 4I44564438

Fax +I 4144566515

Email sorokin@mcw.edu

\begin{abstract}
Studies demonstrate that lipid mediator 20-Hydroxyeicosatetraenoic acid (20-HETE) synthesis and signaling are associated with the growth of cancer cells in vitro and in vivo. Stable 20-HETE agonists promote the proliferation of cancer cells, whereas selective inhibitors of the 20-HETE-producing enzymes of the Cytochrome (CYP450)4A and CYP4F families can block the proliferation of glioblastoma, prostate, renal cell carcinoma, and breast cancer cell lines. A recent observation that the expression of CYP4A/4F genes was markedly elevated in thyroid, breast, colon, and ovarian cancer further highlights the significance of 20-HETEproducing enzymes in the progression of different types of human cancer. These findings provide the rationale for targeting 20-HETE-producing enzymes in human cancers and set the basis for the development of novel therapeutic strategies for anticancer treatment.
\end{abstract}

Keywords: 20-hydroxyeicosatetraenoic acid, CYP4A, CYP4F, HET0016, eicosanoids

\section{Introduction}

The eicosanoid, 20-hydroxyeicosatetraenoic acid (20-HETE), has emerged as a novel signaling molecule contributing to the progression of cancer. ${ }^{1-3}$ Eicosanoids are 20 -carbon bioactive lipid mediators generated by enzymatic oxidation of arachidonic acid (AA). These include prostaglandins (products of cyclooxygenases), leukotrienes (products of lipoxygenases), and hydroxyeicosatetraenoic (HETEs) and epoxyeicosatrienoic acids (EETs) (products of cytochrome P450 enzymes). ${ }^{4}$ Even though eicosanoid-mediated modulation of ion transport, renal and pulmonary functions, as well as vascular tone and reactivity have been universally acknowledged, ${ }^{5,6}$ not until recently has it become evident that these lipid mediators are also involved in carcinogenesis. ${ }^{7,8}$ Prostaglandins have subsequently been the most widely and intensely studied group of eicosanoids in cancer biology. ${ }^{8}$ Among prostaglandins, prostaglandin $\mathrm{E}_{2}\left(\mathrm{PGE}_{2}\right)$ has received the most attention as a potential contributor to cancer progression. ${ }^{9-11}$ Indeed, $\mathrm{PGE}_{2}$ has a potent proproliferative effect, is involved in conferring a multidrug resistance phenotype, ${ }^{12,13}$ and it increases tumor growth in ApcMin/+ and azoxymethane mouse models of colorectal cancer. ${ }^{14} \mathrm{PGE}_{2}$ also reversed nonsteroidal anti-inflammatory druginduced adenoma regression in these mice. Furthermore, inhibition of endogenous $\mathrm{PGE}_{2}$ resulted in the suppression of intestinal tumorogenesis. ${ }^{15}$ These findings are consistent with established $\mathrm{PGE}_{2}$-mediated signaling, which includes, among others, transactivation of endothelial growth factor (EGF) receptor, ${ }^{16-18}$ and peroxisome proliferator-activated receptor $\delta .{ }^{19}$ Activation of these signaling cascades resulted in stimulation of cell migration through increased PI3K-Akt signaling in colon cancer cells and increased intestinal epithelial tumor cell survival. Concordantly, $\mathrm{PGE}_{2}$ has 
also been shown to induce expression of such antiapoptotic proteins as $\mathrm{Bcl}-2,{ }^{20}$ and increase transcriptional activity of a key antiapoptotic regulator, nuclear factor-kappa B $(\mathrm{NF} \kappa \mathrm{B}) .{ }^{21}$ It has also been reported that $\mathrm{PGE}_{2}$ possesses an angiogenic effect. ${ }^{22,23} \mathrm{PGE}_{2}$ reversed the antiangiogenic activity of nonsteroidal anti-inflammatory drugs, whereas homozygous deletion of $\mathrm{PGE}_{2}$ receptor EP2 completely abrogated the induction of vascular endothelial growth factor (VEGF) in APC ${ }^{\Delta 716}$ mouse polyps. ${ }^{24}$ This is consistent with earlier studies showing that $\mathrm{PGE}_{2}$ upregulates VEGF in cultured human fibroblasts, ${ }^{25}$ and increases VEGF and basic fibroblast growth factor expression through the stimulation of extracellular-signal-regulated kinase (ERK)2/c-Jun $\mathrm{N}$-terminal kinase 1 signaling pathways in endothelial cells. ${ }^{26}$ Similarly, while not as well studied as $\mathrm{PGE}_{2}, \mathrm{PGF}_{2 \alpha}$ has been demonstrated to enhance carcinogen-induced transformation of fibroblasts in vitro, ${ }^{7}$ while thromboxane A2 was reported to promote angiogenesis. ${ }^{27}$

Compared with prostaglandins, much less is known about the role of lipoxygenases (LOXs) in cancer. Data are accumulating that support the role of $15-\mathrm{LOX}-1$ as a tumor suppressor, especially in colon cancer. ${ }^{28}$ On the other hand, overexpression of 12-LOX was strongly associated with poor differentiation and invasiveness of prostate cancer. ${ }^{29}$ Further, it has been shown that leukotriene $\mathrm{B}_{4}\left(\mathrm{LTB}_{4}\right)$ levels are increased in human colon and prostate cancers, ${ }^{30,31}$ and the expression of $\mathrm{LTB}_{4}$ receptors is upregulated in human pancreatic cancer. ${ }^{32}$ Additionally, it has been shown that inhibition of $\mathrm{LTB}_{4}$ synthesis leads to reduced esophageal adenocarcinoma in a rat model and that blocking the receptor of $\mathrm{LTB}_{4}$ suppressed the $\mathrm{LTB}_{4}$-stimulated expression of ERK in colon cancer cells. ${ }^{33}$ Other LOX byproducts, such as 12(S) HETE have been reported to mediate the activation of $\mathrm{NF} \kappa \mathrm{B},{ }^{34}$ induce angiogenesis through stimulating VEGF expression in prostate cancer cells, ${ }^{35,36}$ and increase adhesion of B16 murine melanoma cells to endothelial cells via upregulation of $\alpha v \beta 3$ integrin expression. ${ }^{37}$

The role of HETEs and EETs in cancer has been neglected until recently. ${ }^{38}$ There are mounting data that suggest that products of $\omega$-hydroxylases of the cytochrome P450 (CYP) family of proteins, notably 20-HETE, can play an important role in cell growth and cancer development. ${ }^{38}$ In this review, we will summarize the findings that provide the rationale for considering 20-HETE producing enzymes as novel targets for anticancer therapy, describe the potential of available pharmacological agents for interfering with 20-HETE synthesis and signaling, and discuss the potential of their clinical application for cancer treatment.

\section{Cellular synthesis of 20-HETE and other eicosanoids}

AA is metabolized to eicosanoids through three major pathways: the cyclooxygenase (COX), the LOX, and the CYP-450 monooxygenase pathways, which insert oxygen at different positions in AA to generate the wide variety of lipid mediators. AA metabolized by the COX pathway forms prostaglandins (PGs) and thromboxanes. AA metabolized by LOX pathway produces $15(\mathrm{~S}), 12(\mathrm{~S}), 12(\mathrm{R}), 8(\mathrm{~S}), 5(\mathrm{~S})$ HETEs, leukotrienes, and lipoxins. Finally, AA metabolized by the CYP-450 pathway generates 16-, 17-, 18-, 19-, and 20-HETEs and 5-, 6-, 8-, 9-, 11-, 12-, 14-, and 15-EETs. ${ }^{4}$

The COX enzymes (COX1/COX2) catalyze the conversion of AA to an unstable cyclic endoperoxide (prostaglandin $\mathrm{H}_{2}$, $\mathrm{PGH}_{2}$ ), which is further catalytically converted to the various prostanoids including $\mathrm{PGD}_{2}, \mathrm{PGE}_{2}, \mathrm{PGF}_{2 \alpha}$, prostacyclin, and thromboxane $\mathrm{A}_{2}$ via reduction, rearrangement, or isomerization by the terminal synthase enzymes. ${ }^{4}$ It should be noted that 5-, 8-, 12-, and 15-LOX enzymes metabolize AA to several regioisomeric allylic hydroperoxides, which are further reduced into the corresponding leukotrienes and HETEs. ${ }^{4}$ The cytochrome P-450 $\omega$-hydroxylases (CYP4A and CYP4F) metabolize AA to produce HETEs, including 19- and 20-HETE (Figure 1), and cytochrome P-450 epoxygenases (CYP2C and CYP2J) convert AA to the various EETs. To generate 19/20-HETE the $\omega$-hydroxylases of the $4 \mathrm{~A}$ and $4 \mathrm{~F}$ gene families of CYP450 introduce an hydroxyl $(\mathrm{OH})$ group at or near the terminal $\mathrm{sp}^{3}$ carbon group of AA. ${ }^{4,39,40}$ The pathways involved in the metabolism of AA are depicted in Figure 2.

\section{Methods of detecting 20-HETE in cells and tissues}

Due to the chemical and biological complexity of eicosanoids, the measurement of their concentrations in biological samples must be carefully validated and controlled in the laboratory.

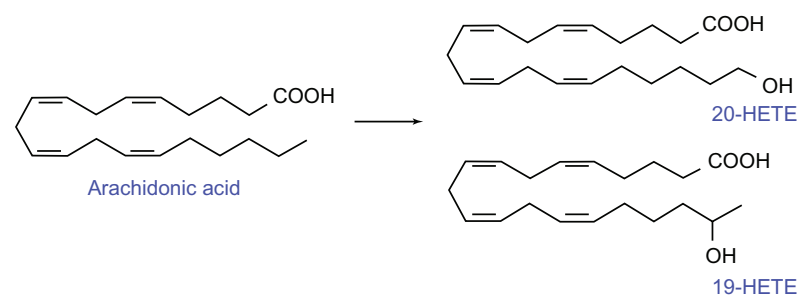

Figure I Synthesis of 20-HETE.

Note: $\omega / \omega-I$ hydroxylases of CYP4A and CYP4F introduce a hydroxyl group into positions 20 or 19 of arachidonic acid to form 19-HETE and 20-HETE, respectively. Abbreviations: 20-HETE, 20-hydroxyeicosatetraenoic acid; CYP, cytochrome P450; 19-HETE, 19-hydroxyeicosatetraenoic acid. 


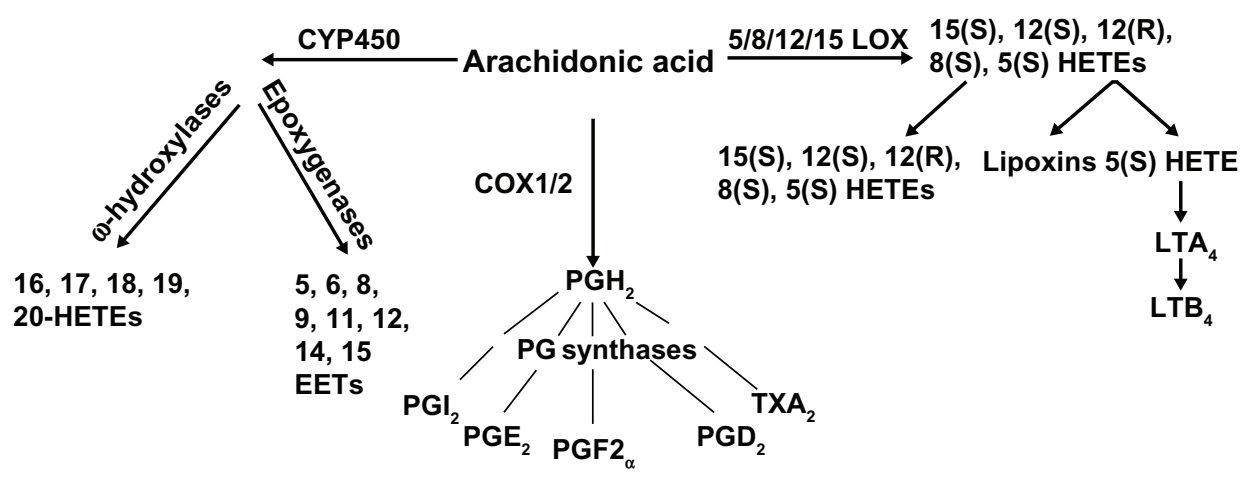

Figure 2 An overview of eicosanoid synthesis pathways.

Note: Schematic overview of three major enzymes of arachidonic acid metabolism and their metabolites.

Abbreviations: CYP, cytochrome P450; LOX, lipoxygenase; EET, epoxyeicosatrienoic acid; PGI, prostacyclin synthase; PGE, prostaglandin E2; PGF2, prostaglandin F2; PGD, prostaglandin D2; TXA 2 , thromboxane A2; LTA, leukotriene A4; $\mathrm{LTB}_{4}$, leukotriene B4; PGH2, prostaglandin H2; COXI/2, cyclooxygenase I/2; HETE, hydroxyeicosatetraenoic acid.

There are several analytical techniques available when it is necessary to determine eicosanoid concentrations in biological samples. In this chapter, we discuss each of these techniques and evaluate the advantages and drawbacks of each methodology.

Radioimmunoassay (RIA) is a commonly used method for the quantitative analysis of eicosanoid levels in biological samples. The assay is based on the competition between the antigen (the eicosanoid being measured) and a constant amount of radioactive homologous antigen for a limited amount of specific eicosanoid antibody. Thus, the necessary reagents include a monospecific antibody, an unlabelled eicosanoid to be used as a standard, and radioactively labeled eicosanoid. The antibody-bound radioactivity is inversely proportional to the concentration of the eicosanoid in the sample. RIA is rapid, sensitive, and relatively inexpensive; ${ }^{4,41}$ however, there are risks associated with using radioactive materials, which accompany all RIA assays.

Similarly, enzyme immunoassay (EIA) is also based on the competition between an eicosanoid and a constant amount of chemiluminescent (eg, acetylcholinesterase or alkaline phosphatase) conjugated eicosanoid for a limited amount of antibodies raised against a particular eicosanoid. The product of the enzymatic reaction is read spectrophotometrically at a certain wavelength after the addition of a corresponding substrate and is inversely proportional to the concentration of the eicosanoid in the samples. EIA kits for 20-HETE measurement (Eagle Biosciences, Nashua, NH, USA; R\&D Inc, Detroit, MI, USA; and ALPCO Diagnostics, Salem, NH, USA), as well as kits for other eicosanoids, are commercially available. While EIA is similar to RIA with regard to sensitivity and specificity, the cost of EIA is much higher. Further, both assays are limited by the fact that antibodies to all the known AA metabolites are not readily available.
Another drawback of these assays is nonspecific binding, which results from the cross-reactivity of the antibodies with other eicosanoids of similar structure leading the investigator to overestimate the concentrations of analytes. Further, both of these techniques allow for the analysis of only one analyte at a time, which is time consuming. ${ }^{4,41}$

Gas chromatography-mass spectrometry (GC-MS) is another technique utilized in the analysis of eicosanoids and is based on the partition of the analyte between the stationary and gaseous phases. This requires molecules that are being analyzed to be volatile and thermally stable at high GC temperatures. To achieve this, polar groups on eicosanoids, which cause tailing during GC-MS, need to be derivatized to more stable trimethylsilyl groups, which is time consuming and complicated. ${ }^{4,41}$

Liquid chromatography-mass spectrometry-mass spectrometry (LC-MS-MS) is a more practical analysis of eicosanoids. In the analysis of eicosanoids by LC-MS-MS, eicosanoids have to be initially extracted by a solid phase, reverse phase, normal phase (silica), and ion exchange columns. Eicosanoids can also be further extracted using liquid extraction, and depending on the eicosanoid being analyzed, one or both of the extraction methods may need to be utilized. The complex mixture of eicosanoids will then need to be separated by liquid chromatography before being introduced into the source of the mass spectrometer, where ionization takes place allowing for the identification of different eicosanoids. Additionally, the use of stable isotopelabeled internal standards in LC-MS-MS prior to extraction is essential for quantitative analysis of the eicosanoids present in cells, urine, plasma, or tissue homogenates. ${ }^{4,41}$ An example of the detection of eicosanoids by LC-MS-MS is shown in Figure 3. We have used this technique quite routinely for the measurement of 20-HETE in tissue and cellular samples. 


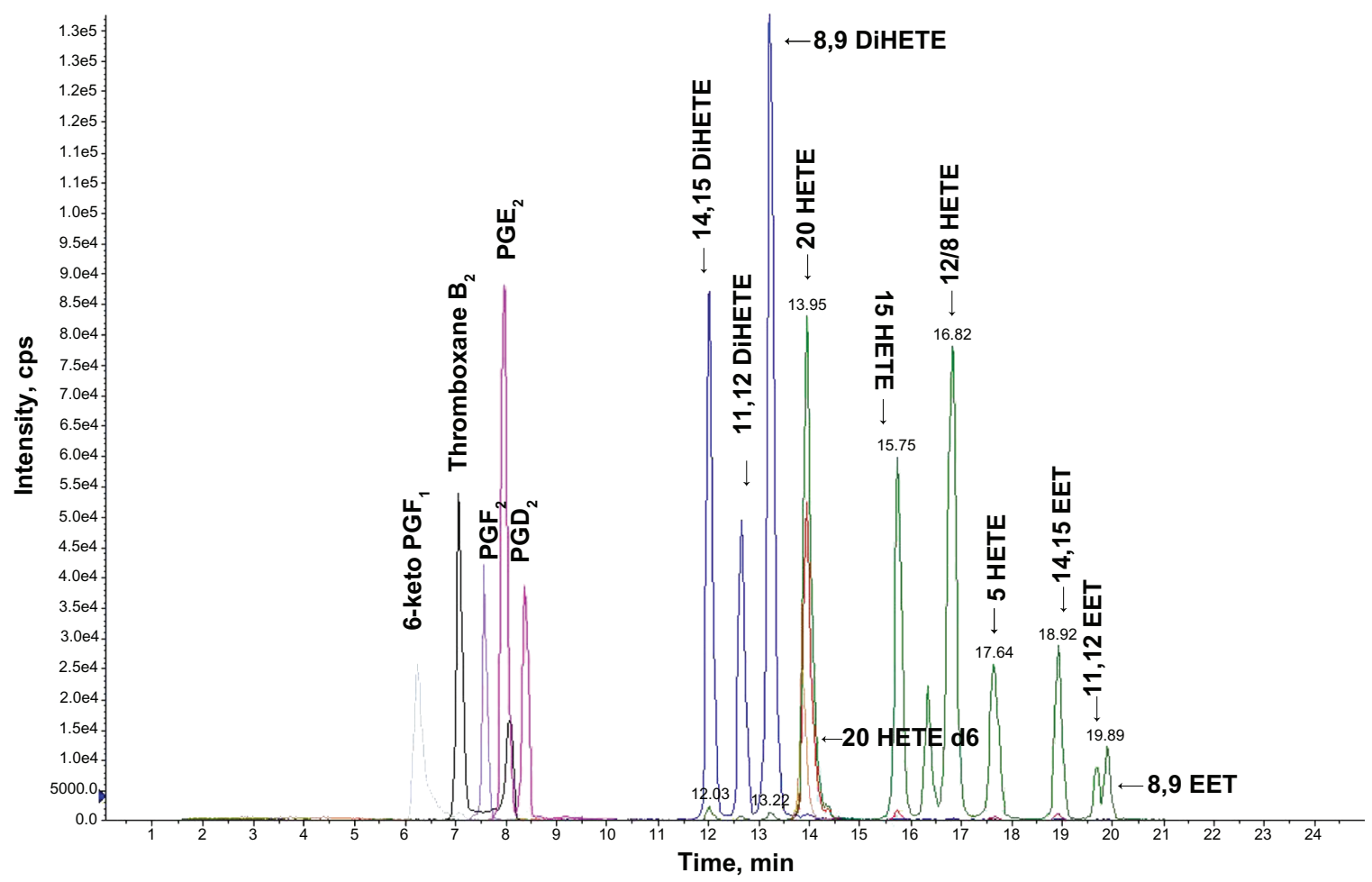

Figure 3 LC-MS-MS detection of HETE standards.

Note: Representative chromatogram generated from LC-MS-MS data, illustrating the separation of various HETEs with different retention times and transitions.

Abbreviations: LC-MS-MS, liquid chromatography-mass spectrometry-mass spectrometry; HETE, hydroxyeicosatetraenoic acid; PG, prostaglandin; DiHETE, diastereomeric 5,6-dihydroxyeicosatetraenoic acid; EET, epoxyeicosatrienoic acid.

While GC-MS and LC-MS-MS are both sensitive and allow for the analysis of multiple analytes simultaneously, the cost is prohibitive, which limits the usage of this method for 20-HETE detection.

In summary, LC-MS-MS and GC-MS are the most reliable and accurate methods for identifying and quantifying 20-HETE and other eicosanoid levels. However, the high cost of these techniques limits the number of replicates per sample, sometimes leading to inconclusive results. Immunoassays, which are less expensive, recently became an alternative detection method for 20-HETE and other eicosanoids for which antibodies are available. They are more practical, as samples can be run in replicates and a larger amount of samples can be assayed; however, immunoassays can also be problematic due to nonspecific binding. Overall, as each of the detection methods listed above has its drawbacks, it is desirable to combine these assays to accurately measure and confirm levels of 20-HETE and other eicosanoids in biological samples.

\section{0-HETE-producing enzymes}

There are four human CYP450 isoforms that catalyze the hydroxylation of AA at the $\omega$ - or 20-carbon to produce 20-HETE; they are CYP4A11, CYP4A22, CYP4F2, and CYP4F3. ${ }^{39,40,42}$ These CYP450 enzymes are encoded by distinct genes and are highly homologous. Analysis of the CYP4A11 gene revealed that, like CYP4A22, it contains 12 exons and eleven introns, and its overall length and exon/ intron structure were similar to those of CYP4A22. However, the physical alignment of CYP4A11 and CYP4A22 genes exposed small insertions and deletions in the introns, with the most conserved being intron 8 , while introns 3,6 , and 9 showed the highest degree of divergence, resulting in a 96\% overall sequence identity between CYP4A11 and CYP4A22 genes. Furthermore, the translated sequences for CYP4A11 and CYP4A22 show that these proteins are of the same length and differ only by 25 residues. ${ }^{43}$ Similarly, CYP4F2 and CYP4F3 genes share $80 \%$ amino acid identity, with highly similar organization of genes. ${ }^{44}$ Of the four 20-HETE-producing enzymes, CYP4F2 is considered the major enzyme involved in the production of 20-HETE in humans accounting for about $70 \%$ of 20 -HETE production, with an apparent $K_{\mathrm{M}}$ of $23.5 \mu \mathrm{M}$ and $V_{\max }$ of $7.4 \mathrm{~min}^{-1}$ while CYP4A11 has a tenfold higher $K_{\mathrm{M}}$ of $228.2 \mu \mathrm{M}$ and $V_{\max }$ of $49.1 \mathrm{~min}^{-1}$. Besides kinetic studies, the role of CYP4F2 as the predominant AA $\omega$-hydroxylase in the production of 20-HETE, has been further confirmed by immunoinhibition studies, which showed that antibodies to CYP4F2 elicited 
marked inhibition (93\%) of 20-HETE formation, whereas antibodies to CYP4A11 only elicited $13 \%$ inhibition. ${ }^{42}$ It was recently reported that overexpression of a novel CYP4 family member, CYP4Z1, was associated with increased levels of 20-HETE in breast cancer cells. ${ }^{45}$

The abundance of 20-HETE-producing enzymes in mammals makes it hard to use the knockout approach to study their relevance for cancer progression. ${ }^{39}$ In mice, the two enzymes primarily responsible for 20-HETE production are CYP4A10 and CYP4A12, with CYP4A12 being the predominant 20-HETE synthase in the mouse kidney. ${ }^{46}$ In rats, there are four isoforms of 20-HETE-producing enzymes: CYP4A1, CYP4A2, CYP4A3, and CYP4A8. Among them, CYP4A1 has the highest catalytic activity toward AA $\omega$-hydroxylation. It is followed by CYP4A2 and CYP4A3, which display similar activity. CYP4A8 also contributed to 20-HETE formation in rat kidney. ${ }^{47}$

Disruption of the mouse CYP4A10 gene caused hypertension, which was dietary salt sensitive. ${ }^{48}$ CYP4A12 knockout mice were not described. Recently, rat knockouts of CYP4A2 and CYP4A3 were generated using a zinc finger nuclease approach as a part of the PhysGen Knockout program ("Mechanistic Characterization of Genes for Hypertension and Renal Disease") at the Medical College of Wisconsin (Milwaukee, WI, USA). This program aimed to knock out a large number of genes, nominated by genomewide association studies as relevant for the development of hypertension and renal disease, and the generated rat strains are available for distribution. So far, neither mouse nor rat knockouts of 20-HETE-producing enzymes have been utilized in cancer-related studies.

\section{0-HETE actions and signaling}

It should be noted that 20 -HETE, being a potent vasoconstrictor, plays a complex role in the regulation of blood pressure and vascular tone. The vasoconstriction activity of 20-HETE in rat aortic rings was among the first 20-HETE actions described. ${ }^{49}$ Specifically, 20-HETE mediates autoregulation of cerebral blood flow. ${ }^{50}$ Renal actions of 20-HETE are linked to the regulation of $\mathrm{Na}^{+}$transport and the pressurenatriuresis response. ${ }^{51,52}$ Importantly, 20-HETE inhibits $\mathrm{Na}^{+}$ transport in renal proximal tubules, ${ }^{53}$ but not in cortical collecting ducts, where inhibition is likely to be mediated by EETs. ${ }^{54,55}$ Inhibitors of 20-HETE formation promote saltsensitive hypertension and renal injury in the rat model. ${ }^{56}$ For an excellent summary of the renal and vascular actions of 20-HETE and the role of 20-HETE in the control of hypertension, see the review by Williams et al. ${ }^{52}$ The role of
20-HETE in physiological and pathological vascularization was also recently reviewed. ${ }^{57}$

In addition to vasoactive effects, 20-HETE stimulates mitogenic and angiogenic responses both in vitro and in vivo. ${ }^{39}$ Both mitogenic and angiogenic activities are important for the ability of 20-HETE to support the proliferation of cancer cells and tumor growth; 20-HETE has been shown to induce cell proliferation and DNA synthesis in vascular smooth muscle and proximal tubule cell cultures, as well as in a number of cancer cell lines. The proangiogenic activity of 20-HETE with regard to endothelial cell population is through the promotion of proliferation, migration, and cell survival. These 20-HETE actions were accompanied by increased VEGF expression and release. ${ }^{1,58}$ VEGF is the major driver of tumor angiogenesis. ${ }^{59}$ These studies support the idea that 20-HETE signaling contributed to cell growth, invasion, and angiogenesis in the regulation of tumor development.

The biggest challenge with attempts to define 20-HETE signaling is that to date, the specific cellular receptor of 20-HETE has not been identified. In striking contrast to PGs (whose G-protein coupled receptors are well studied and characterized), no reliable information about the nature of HETE receptors in general and the 20-HETE receptor in particular, is available. Correspondingly, specific 20-HETE antagonists preventing the binding of 20-HETE to its receptor are missing from the arsenal of tools for the treatment of 20-HETEmediated pathologies, a circumstance which continues to delay the development of 20-HETE-focused therapeutic strategies. The situation was improved with the introduction of specific inhibitors of 20-HETE synthesis and antagonists of 20-HETE signaling, which will be discussed below. It also must be taken into consideration that enzymes that synthesize 20-HETE are microsomal enzymes, and 20-HETE, when released intracellularly, could act as an intracellular second messenger and interact directly with intracellular targets. Therefore, the possibility that 20-HETE and other HETEs act without binding to canonical transmembrane receptors cannot be ruled out, even though it would make them different from other eicosanoids.

In the absence of an identified 20-HETE receptor, studies of 20-HETE signaling are limited to description of cellular signaling pathways being activated following addition of 20-HETE to cultured cells and administration of 20-HETE to animals. Multiple signaling cascades were reported to be activated by 20 -HETE in a variety of cell systems. ${ }^{57,60,61}$ In addition, 20-HETE induced activation of Raf/MEK/ERK, signaling a cascade secondary to the activation of c-Src and EGF receptor in renal epithelial cells. ${ }^{62}$ Moreover, 20-HETE triggers NF $\kappa \mathrm{B}$ and ERK activation in 
human endothelial cells. ${ }^{60}$ Furthermore, 20-HETE can also activate the small-GTPase Ras, which plays a critical role in the regulation of cell growth; ${ }^{63}$ 20-HETE was reported to signal through the cyclic adenosine monophosphate/ protein kinase A (PKA)-phosphorylase kinase-glycogen phosphorylase pathway to induce hyperglycemia. ${ }^{64} \mathrm{NAHPH}-$ oxidase-derived superoxide mediated 20-HETE-induced activation of L-type $\mathrm{Ca}^{2+}$ channels via a $\mathrm{PKC}$-dependent mechanism in cardiomyocytes. ${ }^{61}$ A diagram showing the various 20-HETE-mediated signaling pathways and their (probable) interactions is included (Figure 4).

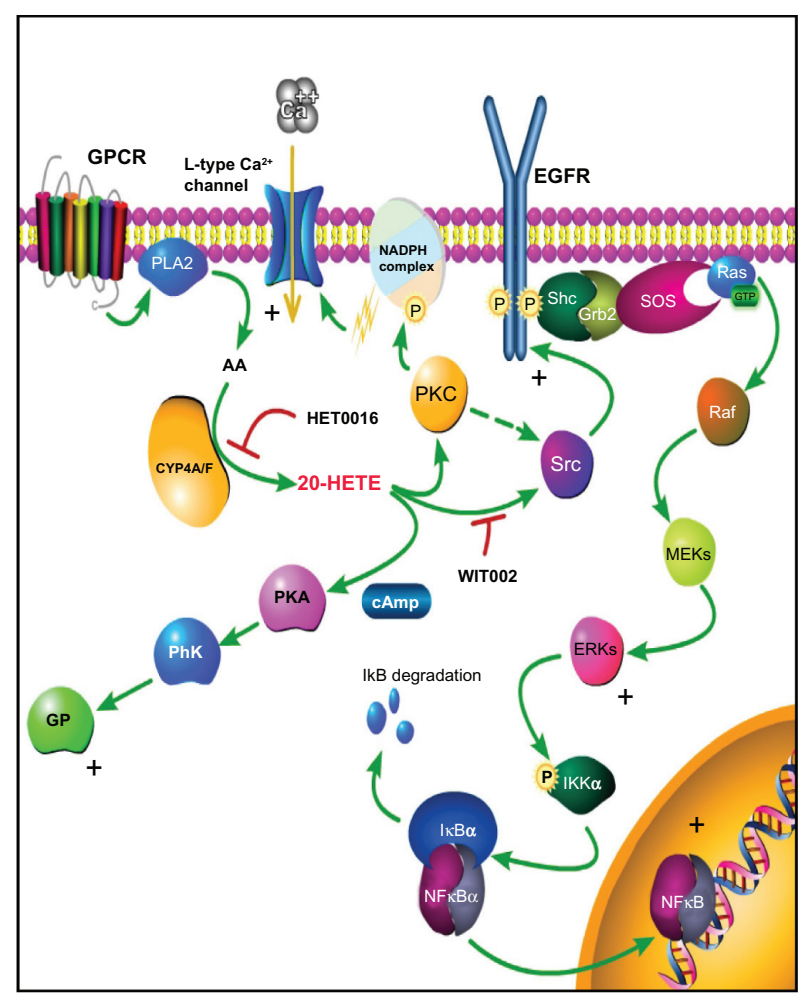

Figure 4 Proposed mechanism of action of 20-HETE.

Notes: Mitogens and ligands of G-protein-coupled receptors activate PLA2 and induce release of arachidonic acid, which is converted by CYP4A/F to 20-HETE. Then, 20-HETE, acting presumably via Src, promotes tyrosine phosphorylation of EGFR and consequently activates the Ras-Raf-MEK-ERK cascade, which leads to the proliferation of cancer cells. One of cytoplasmic targets of ERK is I-kappaB kinase-alpha, which phosphorylates I-kappaB-alpha, resulting in the degradation of I-kappaB-alpha by the proteosome and the translocation of NFKB to the nucleus, where it positively regulates the transcription of a number of genes involved in immune and inflammatory responses including VEGF. In addition, 20-HETE also activates cAMP-dependent PKAphosphorylase kinase-GP (glycogen phosphorylase pathway) to induce hyperglycemia. Besides, 20-HETE stimulates NADPH oxidase-derived superoxide production, which activates L-type $\mathrm{Ca}^{2+}$ channels via a PKC-dependent mechanism. Inhibitory interactions are shown by red lines with bars. Stimulatory interactions are shown by green lines with arrows. Activation of the principal signaling cascade is shown by + .

Abbreviations: 20-HETE, 20-hydroxyeicosatetraenoic acid; GPCR, G proteincoupled receptor; EGFR, endothelial growth factor; PLA2, phospholipase A2; $\mathrm{NADPH}$, nicotinamide adenine dinucleotide phosphate; SOS, salt overly sensitive; AA, arachidonic acid; CYP, cytochrome P450; PKC, protein kinase C; PKA, protein kinase A; PhK, phosphorylase kinase; GP, glycogen phosphorylase pathway; CAMP, cyclic adenosine monophosphate; MEK, MAP kinase kinase; ERK, extracellular signalregulated kinases; IKB $\alpha$, I-kappaB-alpha; NFKB, nuclear factor-kappaB;VEGF, vascular endothelial growth factor; HET00I6, N-Hydroxy-N'-(4-butyl-2-methylphenyl) formamidine; WIT002, 20-hydroxyeicosa-6(Z), I5(Z)-dienoic acid.

\section{Expression of 20-HETE-producing enzymes in human cancers}

While 20-HETE induces mitogenic and angiogenic responses in cancer cells and inhibitors of the 20-HETE pathway have been shown to reduce the growth of brain and kidney tumors at least in animal models, ${ }^{65,66}$ the expression pattern of 20-HETE-producing enzymes in human cancers has not been addressed. We have demonstrated that the 20-HETE-producing enzymes CYP4A/F are upregulated in human cancer tissue samples. ${ }^{63}$ In this study, TissueScan cancer survey panels obtained from OriGene (OriGene Technologies, Inc, Rockville, MD, USA) containing prenormalized cDNA from multiple cancer tissues were used to run real-time polymerase chain reaction (Sybr Green ${ }^{\circledR}$, Life Technologies, Carlsbad, CA) to analyze the expression of CYP4A and CYP4F genes at the messenger ribonucleic acid (mRNA) level. The tissue samples used for each type of TissueScan panel were obtained from independent patients, covered various disease stages, and matched control normal tissues, and these samples are included for comparison between normal and disease samples. Analysis of 20-HETEproducing CYP enzymes in various human cancer tissues demonstrated that CYP4A/F enzymes were upregulated at the mRNA level in human thyroid, breast, colon, and ovary cancers when compared to corresponding normal tissue. ${ }^{63}$ Analysis of human lung cancer tissue samples also revealed increased levels of CYP4F/A enzymes; even though a dramatic increase of expression of 4F2 and 4F 3 were detected only in one of nine cancer tissue samples, two other cancer samples (indicated as E8 and E10) demonstrated increased expression of $4 \mathrm{~F} 2$, which was not detectable in matched control normal tissues (Figure 5). Most CYP450 enzymes are expressed in the liver and are involved in the metabolism of drugs and foreign chemicals. Both normal and cancerous liver cells are characterized by the increased expression of 20-HETE-producing enzymes. The prostate is also rich with AA-metabolizing enzymes. Any increase in the expression of 20-HETE-producing enzymes in the liver and prostate will be more difficult to detect because it will be masked by substantial expression in normal cells; this is not the case with other tissues. Primers used in real-time polymerase chain reaction experiments to detect the expression of CYP4A/F genes at the mRNA level are listed in Table 1. Using Western blot analysis of an OncoPair INSTA-Blot ${ }^{\mathrm{TM}}$ PVDF membrane (IMGENEX Corporation, San Diego, CA, USA) containing 14 lanes of alternating ovarian tumor and matched normal adjacent tissue lysates from seven patient donors (IMGENEX Corporation) and immunohistochemistry analysis, we further 


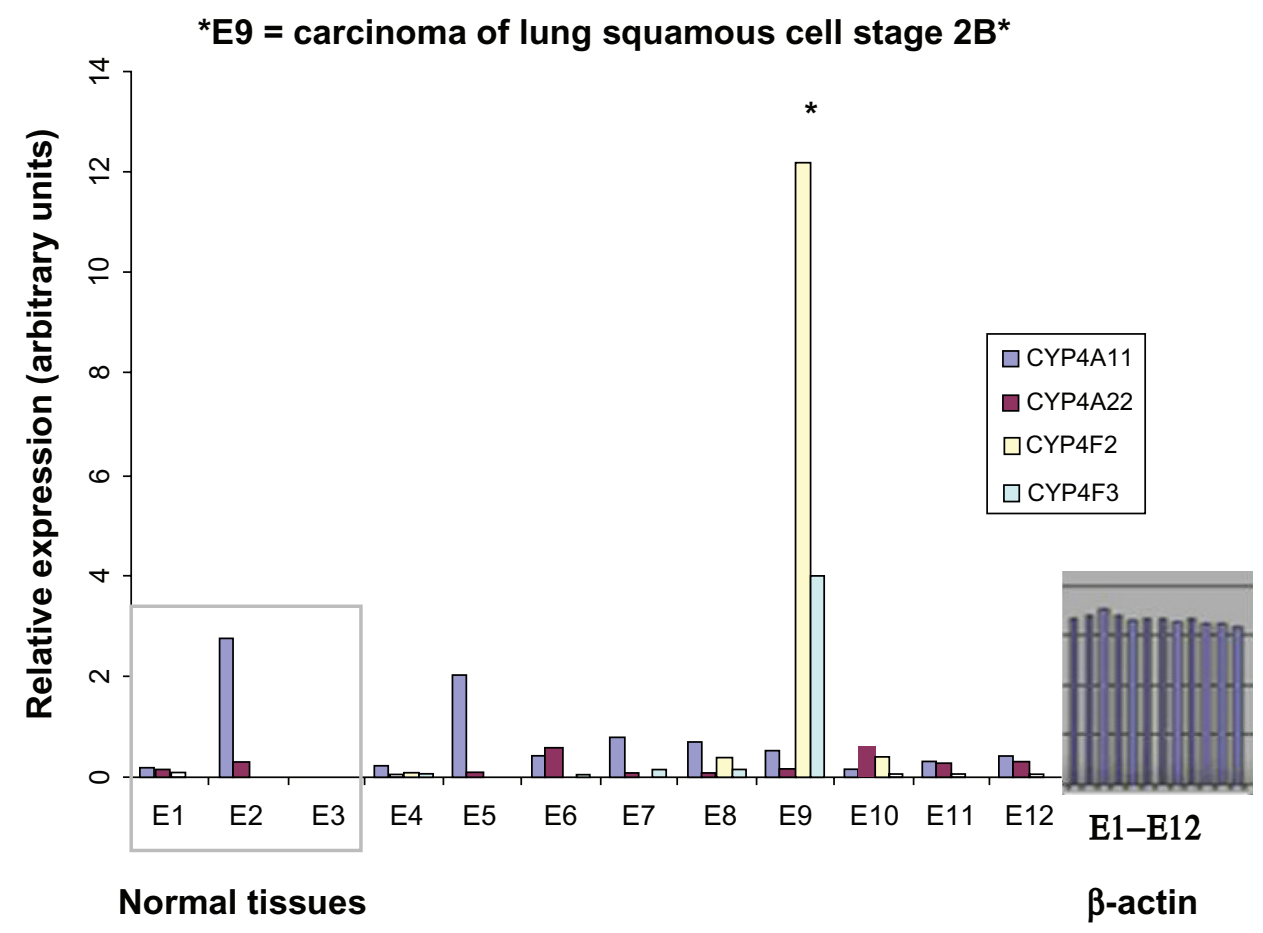

Figure 5 Expression of CYP4A and CYP4F genes at the mRNA level is elevated in human lung cancer tissue samples.

Notes: Real time-PCR of lung TissueScan cancer survey panel using primers for CYP4A/F genes. Matched control normal tissues are included for comparison between normal and disease samples. The amount of PCR product is correlated with the amount of original RNA transcript and the data are expressed in arbitrary units. *Indicates tumor samples demonstrating striking up-regulation in CYP4A/F enzymes.

Abbreviations: CYP, cytochrome P450; mRNA, messenger ribonucleic acid; PCR, polymerase chain reaction; RNA, ribonucleic acid.

demonstrated that the expression of CYP4F2 (the major 20-HETE-producing enzyme) was increased at the protein level in ovarian cancer when compared to normal adjacent tissue. ${ }^{63}$

\section{Agonists, antagonists, and inhibitors of the synthesis of 20-HETE}

A hydroxyphenylformamidine derivative, HET0016 [N-hydroxy-N'-(4-butyl-2-methylphenyl)-formamidine], was shown to be a potent and selective inhibitor of 20-HETE synthesis in rat and human renal microsomes. ${ }^{67}$ To retain high inhibitory activity, N-hydroxyformamidine had to be unsubstituted, with the substituent at the paraposition of N-hydroxyformamidine decreasing the inhibitory activity most drastically. ${ }^{68}$
In the absence of antagonists preventing the binding of 20-HETE to its probable transmembrane receptor, 20-hydroxyeicosa-6(Z),15(Z)-dienoic acid (WIT002) has emerged as an antagonist of 20-HETE signaling (Figure 6). ${ }^{69}$ WIT002 is a noncyclooxygenase metabolizable stable analog of 20-HETE, which antagonizes the vasoconstrictor effects of 20-HETE in vitro and in vivo. ${ }^{69,70}$ WIT002 also inhibits the stimulatory effect of 20-HETE upon the platelet-derived growth factor-mediated migration of vascular smooth muscle cells. ${ }^{71} \mathrm{~N}$-[20-hydroxyeicosa$6(Z), 15(Z)$-dienoyl]glycine $(6,15-20$-HEDGE) is an analog of WIT002 that may be more efficacious because of the addition of a glycine group, which may help the compound enter cells or prolong its action by protecting it from $\beta$-oxidation. In addition, synthetic stable analogs of

Table I Primers used to detect human genes encoding CYP4A/F by real-time PCR

\begin{tabular}{|c|c|c|}
\hline Enzyme & Forward & Reverse \\
\hline CYP4AII & 5'-ATGAAGTGTGCCTTCAGCCA-3' & 5'-AAGGCATTCCTCACACGGG-3' \\
\hline CYP4A22 & 5'-AATGGGAAGAGCTCCTTGGC-3' & 5'-AAGGCATTCCTCATACAGC-3' \\
\hline CYP4F2 & 5'-AAGCACCCAGAATACCAGGA-3' & 5'-TCATGCACATGGTCAGGAAG-3' \\
\hline CYP4F3 & 5'-CTGTCGGCAGGAGGTACAAG-3' & 5'-CCTCAGGCTCTCСTTAATGC-3' \\
\hline
\end{tabular}

Note: The 20-HETE-producing CYP450 isoform-specific primer sequences to detect the expression of CYP4A and CYP4F genes at the mRNA level in human cancer tissues are outlined.

Abbreviations: CYP, cytochrome P450; PCR, polymerase chain reaction; 20-HETE, 20-hydroxyeicosatetraenoic acid; mRNA, messenger ribonucleic acid. 
20-HETE N-[20-hydroxyeicosa-5(Z),14(Z)-dienoyl]glycine (5,14-HEDGE) and 20-hydroxyeicosa-5(Z), 14(Z)-dienoic acid (5,14-20-HEDE) (also termed WIT003) were shown to prevent the impairment of cardiorenal functions suggesting a therapeutic potential for 20-HETE analogs. ${ }^{72,73}$

The question of the specificity of inhibitors of 20-HETE synthesis and signaling is a particularly important one. The ability of HET0016 to specifically inhibit the formation of 20-HETE in vivo has been confirmed using LC-MS-MS profiling of all the COX, LOX, and CYP450 eicosanoids in a variety of tissues following in vitro and in vivo administration. ${ }^{74}$ The data supporting the specificity of the agonist WIT003 and the antagonist 6,15-20-HEDGE is less direct. $^{69}$

\section{0-HETE in cancer cell proliferation and tumor growth}

Despite multiple reports of the anticancer activity of inhibitors of 20-HETE synthesis and signaling, there is a shortage of data that demonstrate increased levels of 20-HETE in human cancers. One example is provided by prostate cancer patients, who were shown to have urinary levels of free 20-HETE that were significantly higher than those of normal men, even though a correlation between the concentration of 20-HETE and grade of tumor was not found. ${ }^{75}$

The human glioblastoma cell line, U251, is a malignant glioma cell model, which recapitulates the most prominent histological and immunohistochemical features of human glioblastoma multiforme, a highly aggressive brain tumor with a very poor prognosis. ${ }^{76}$ HET0016 decreased both basal and EGF-induced U251 cell proliferation, an effect that was nullified by the addition of the 20-HETE agonist, WIT003. ${ }^{77}$ HET0016 also reduced angiogenic response to U251 cells measured by a cornea pocket angiogenesis assay. ${ }^{78}$ The 9L gliosarcoma cell line has been extensively used to study chemotherapy and radiation effects upon growth of glioma cells, even though the 9L glioma model is characterized by significant differences from human glioblastoma multiforme. ${ }^{76}$ HET0016 efficiently inhibited 9L cell proliferation, induced apoptosis in these cells, and

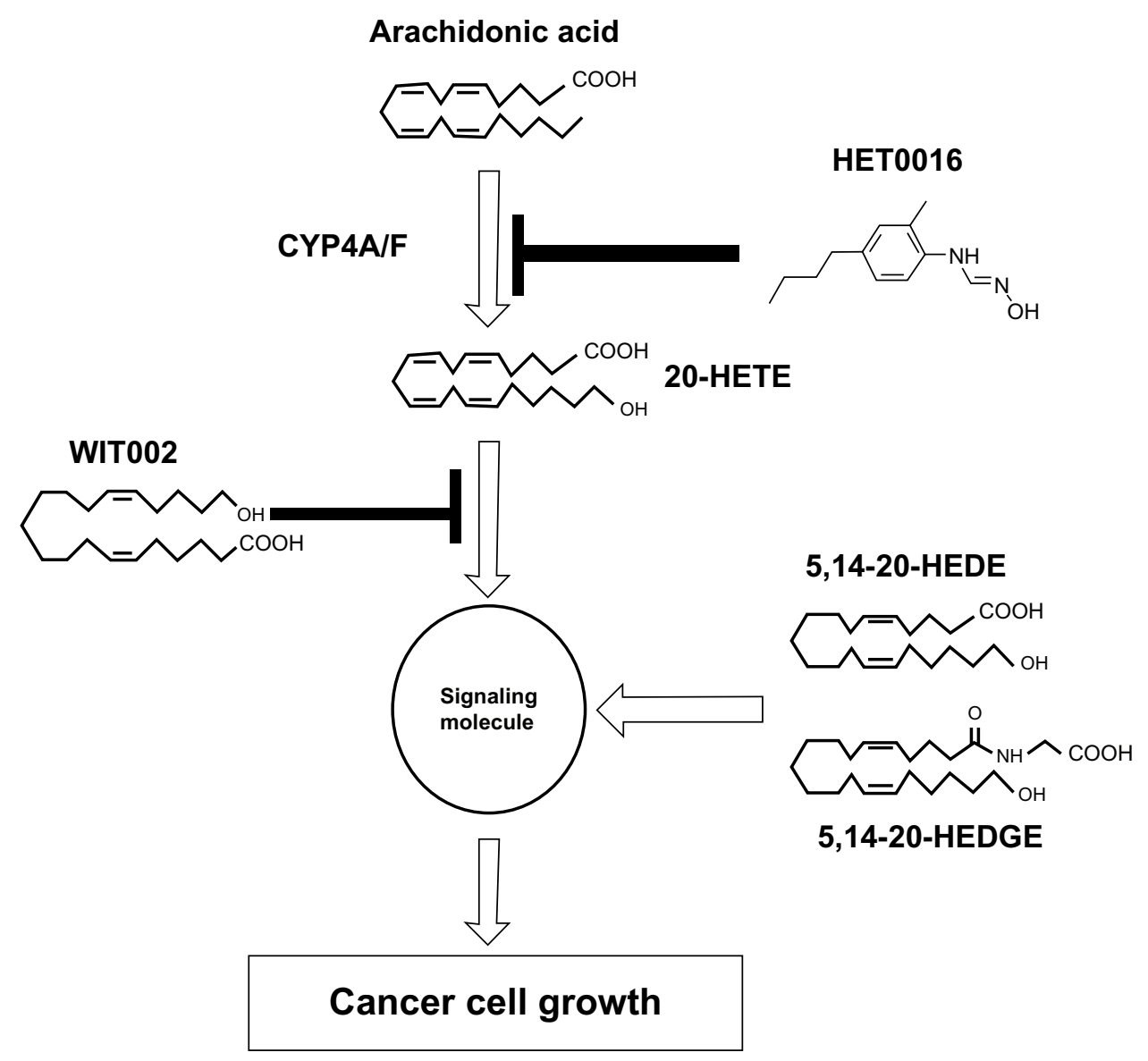

Figure 6 Inhibitors, agonists, and antagonists of 20-HETE.

Note: Depicted are the chemical structures of inhibitors of 20-HETE producing $\omega$-hydroxylases as well as 20-HETE analogs that exhibit agonist or antagonist activity. Abbreviations: 20-HETE, 20-hydroxyeicosatetraenoic acid; 5, I4-20-HEDGE, N-[20-hydroxyeicosa-5(Z), 14(Z)-dienoyl]glycine; 5, I4-20, -HEDE, -20-hydroxyeicosa-5(Z), I4(Z)-dienoic acid. CYP450, Cytochrome P450; WIT002-20-hydroxyeicosa-6(Z), I5(Z)-dienoic acid; HET00I6, N-Hydroxy-N'-(4-butyl-2-methylphenyl) formamidine. 
prevented the proliferative effect of platelet-derived growth factor. ${ }^{65}$ Furthermore, HET0016 also prevented the growth of 9L cells in vivo, when 9L cells were implanted into the forebrain of Fisher rats. In the absence of HET0016, control animals implanted with 9L cells display rapidly growing tumor, whereas rats treated with HET0016 exhibited much smaller tumors with a lesser degree of vascularization. ${ }^{65}$ Nevertheless, careful consideration should be implemented when interpreting HET0016 anticancer actions in U251 and 9L cells, because both $\mathrm{U} 251$ cells and 9L cells failed to synthesize 20-HETE in the presence of AA. ${ }^{77}$ One possible explanation is that 20-HETE synthesized in these cells is rapidly metabolized either by $\beta$-oxidation or by $\mathrm{COX}$, and therefore escapes detection by LC-MS-MS. ${ }^{39}$ The other possibility is that mechanisms of HET0016 action are independent of the inhibition of 20-HETE synthesis in U251 and 9L cells. However, the enforced expression of CYP4A1 in U251 cells caused an increased cell growth both in vitro and in vivo, strongly supporting the significant role of 20-HETE in the progression of glioblastomas. ${ }^{79}$

Non-small-cell lung cancer is among the leading causes of cancer death in the world; 20-HETE generated by CYP4A11 promoted lung cancer angiogenesis and metastasis by upregulation of VEGF and Matrix metallopeptidase 9 (MMP-9) via PI3 kinase and ERK1/2 signaling in human non-small cell lung cancer cells. ${ }^{80}$ In addition, 20-HETE signaling was also shown to play a role in tumor angiogenesis and growth in human breast cancer. ${ }^{45}$ Analysis of mRNA levels encoding 20-HETE-producing CYP enzymes revealed increased levels of CYP 4F2 in some human lung cancer tissue samples (Figure 5).

With an estimated 64,770 new cases of cancers arising from the kidney and renal pelvis in the USA in 2012, renal cell carcinoma is among the leading causes of cancer death. Renal cancer is notoriously resistant to conventional therapies (chemotherapy, hormonal therapy, and radiotherapy), and metastatic forms of clear-cell renal carcinoma are usually associated with very poor patient survival rates ${ }^{81}$ Thus, the lack of an effective therapy demands the urgent investigation and development of any novel treatment strategy. Notably, HET0016 and WIT002 inhibit the proliferation of two different human renal cell carcinoma cell lines, 786-O and 769-P, in vitro, whereas the proliferation of primary normal human proximal tubule epithelial cells was not affected by these drugs. ${ }^{66}$ Both the TNF-related apoptosis- inducing ligand (TRIAL) -sensitive renal cell carcinoma line 769-P and the TRAIL-resistant renal cell carcinoma line 786-O were equally sensitive to the antiproliferative effects of HET0016.
These selective antiproliferative effects of HET0016 and WIT002 on renal cancer cells are of particular interest, since renal cell carcinomas are highly refractory to conventional chemotherapy and even radiation therapy. WIT002 was able to decrease the growth of tumors arising from human kidney cancer epithelial cells in vivo. ${ }^{66}$ These data were the first to indicate the ability of this class of agents to suppress the growth of tumors of human origin.

Overall, 20-HETE plays an important role in the proliferation of prostate cancer cells, both androgenresponsive LNcAP and androgen-nonresponsive PC3 (personal communication from R Roman, Jackson, MS, USA).$^{82}$ CYP4F $/ 3$ might be the source of androgen-driven 20-HETE synthesis via androgen receptor-dependent pathways.

In summary, the addition of inhibitors of 20-HETE synthesis and signaling significantly inhibited the growth of cancer cells both in vitro and sometimes in vivo. Such results have been obtained using human prostate cancer cells, MDA-MB 231 breast cancer cells (personal communication from R Roman, Jackson, MS, USA), U235, 9L and RG3 glioblastoma cell lines, as well as 780P and 769P renal epithelial cancer cell lines. Together with data demonstrating an increased level of mRNA encoding enzymes responsible for 20-HETE generation, these results provide a compelling reason to study the role of 20-HETE in promoting the proliferation of several forms of human cancer.

\section{Clinical potential of targeting 20-HETE-producing enzymes}

Despite dramatic advancements in the treatment of some types of cancer, effective clinical therapies for common human cancers such as lung, ovarian, and renal cancers remain limited. An involvement of AA pathways in the proliferation of different forms of cancer is well documented and there are multiple studies addressing the role of cyclooxygenases and LOX in particular types of cancer. ${ }^{83-87}$ These results have raised enthusiasm for the use of COX-2 inhibitors for anticancer therapy, but the risk of cardiovascular thrombotic events associated with the usage of selective COX-2 inhibitors is a significant concern. ${ }^{88,89}$ Recent studies that have demonstrated the antiproliferative effect of inhibitors of 20-HETE synthesis and the overexpression of CYP4A/F enzymes in human cancers (Table 2) suggest that targeting enzymes responsible for the generation of 20-HETE could be an alternative therapeutic approach for cancer treatment. So far, the role of the products of cytochrome P450 enzymes in control of cancer is insufficiently studied ${ }^{87}$ and there 
Table 2 Expression of CYP4A and CYP4F in human cancer samples and the effects of inhibitors of 20-HETE synthesis and signaling upon cancer cells of different origin

\begin{tabular}{|c|c|c|c|c|c|c|}
\hline $\begin{array}{l}\text { Human } \\
\text { cancer } \\
\text { type }\end{array}$ & $\begin{array}{l}\text { Estimated new } \\
\text { cases in the United } \\
\text { States in } 2012\end{array}$ & $\begin{array}{l}\text { Estimated deaths } \\
\text { in the United } \\
\text { States in } 2012\end{array}$ & $\begin{array}{l}\text { Increased expression } \\
\text { of CYP4A or CYP4F } \\
\text { enzymes in cancer tissues }\end{array}$ & $\begin{array}{l}\text { Antiproliferative } \\
\text { effect of } \\
\text { HET0016 }\end{array}$ & $\begin{array}{l}\text { Antiproliferative } \\
\text { effect of WIT002 }\end{array}$ & References \\
\hline $\begin{array}{l}\text { Breast } \\
\text { cancer }\end{array}$ & $\begin{array}{l}226,870 \text { (female) } \\
2190 \text { (male) }\end{array}$ & $\begin{array}{l}39,510 \text { (female) } \\
410 \text { (male) }\end{array}$ & $\begin{array}{l}\text { 4F2, 4AII, } \\
\text { CYP4ZI }\end{array}$ & Yes & Not studied & 63,45 \\
\hline $\begin{array}{l}\text { Colon and } \\
\text { rectal cancer }\end{array}$ & $\begin{array}{l}103,170 \text { (colon) } \\
40,290 \text { (rectal) }\end{array}$ & $\begin{array}{l}51,690 \text { (colon and } \\
\text { rectal combined) }\end{array}$ & $4 \mathrm{~F} 2,4 \mathrm{~A} 22,4 \mathrm{~F} 3$ & Not studied & Not studied & 63 \\
\hline $\begin{array}{l}\text { Ovarian } \\
\text { cancer }\end{array}$ & 22,280 & 15,500 & $4 \mathrm{AlI}, 4 \mathrm{~A} 22,4 \mathrm{~F} 2$ & Not studied & Not studied & 63 \\
\hline $\begin{array}{l}\text { Kidney } \\
\text { cancer }\end{array}$ & 64,770 & 13,570 & & Yes & Yes & 66 \\
\hline Lung cancer & 226,160 & 160,340 & $4 \mathrm{~F} 2$ & Yes & Yes & 63,80 \\
\hline $\begin{array}{l}\text { Prostate } \\
\text { cancer }\end{array}$ & $24 I, 740$ & 28,170 & $\begin{array}{l}\text { Both normal and cancer tissues } \\
\text { have high levels of expression }\end{array}$ & Yes & Not studied & 63,82 \\
\hline $\begin{array}{l}\text { Thyroid } \\
\text { cancer }\end{array}$ & 56,460 & 1780 & $4 \mathrm{~A} I \mathrm{I}, 4 \mathrm{~A} 22,4 \mathrm{~F} 2$ & Not studied & Not studied & 63 \\
\hline $\begin{array}{l}\text { Liver } \\
\text { cancer }\end{array}$ & 28,720 & 20,550 & $\begin{array}{l}\text { Both normal and cancer tissues } \\
\text { have high levels of expression }\end{array}$ & Not studied & Not studied & 63 \\
\hline Brain tumor & 22,910 & 13,700 & & Yes & Yes & $65,77,79$ \\
\hline
\end{tabular}

Abbreviations: CYP, cytochrome P450; 20-HETE, 20-hydroxyeicosatetraenoic acid, HET00 I6, N-Hydroxy-N'-(4-butyl-2-methylphenyl) formamidine; WIT002, 20-hydroxyeicosa6(Z), I5(Z)-dienoic acid

are no cancer-related clinical trials focusing on 20-HETE synthesis and signaling. The tumor histological type could influence the pharmaceutical agents' capacity to decrease 20-HETE production or signaling. ${ }^{80}$ It is necessary to confirm the mechanism of HET0016 action and identify molecules that are the direct targets of 20-HETE in cancer cells. Furthermore, even though an overexpression of CYP4A/F enzymes has been shown in different types of human cancer (Table 1), studies using a larger number of human tumor samples will be needed to ascertain that the upregulation of CYP4A/F expression occurs in different types of human cancers. These deficiencies notwithstanding, the potential of targeting 20-HETE-producing enzymes to develop into a novel therapeutic strategy for anticancer treatment is high.

\section{Summary}

The CYP4A and CYP4F families of cytochrome P450 enzymes catalyze the omega-hydroxylation of AA to form the lipid mediator, 20-HETE. ${ }^{90,91}$ Furthermore, 20-HETE stimulates mitogenic and angiogenic responses in vitro and in vivo; ${ }^{92}$ it also contributes to cancer cell proliferation and tumor growth. ${ }^{65}$ The stable 20-HETE agonists promote the proliferation of cancer cells, whereas selective inhibitors of the CYP4A and CYP4F families prevent the proliferation of glioblastoma, prostate, renal adenocarcinoma, and breast cancer cell lines. mRNAs encoding CYP4A/4F enzymes are markedly elevated in thyroid, breast, colon, and ovarian cancer. These findings provide the rationale for targeting 20-HETE-producing enzymes in human cancers and could be the basis for the development of novel therapeutic strategies for anticancer treatment.

\section{Acknowledgments}

Supported by following grants: Johnson \& Johnson grant; Wisconsin Breast Cancer Showhouse Research Grant; NIH grant R21DK088018; Fraternal Order of Eagles Research Grant; and a grant from the Advancing a Healthier Wisconsin Program and The Medical College of Wisconsin Cancer Center.

\section{Disclosure}

The authors report no conflicts of interest in this work.

\section{References}

1. Guo AM, Arbab AS, Falck JR, et al. Activation of vascular endothelial growth factor through reactive oxygen species mediates 20-hydroxyeicosatetraenoic acid-induced endothelial cell proliferation. J Pharmacol Exp Ther. 2007;321(1):18-27.

2. Stec DE, Gannon KP, Beaird JS, Drummond HA. 20-hydroxyeicosatetraenoic acid (20-HETE) stimulates migration of vascular smooth muscle cells. Cell Physiol Biochem. 2007;19(1-4):121-128.

3. Lin F, Rios A, Falck JR, Belosludtsev Y, Schwartzman ML. 20-hydroxyeicosatetraenoic acid is formed in response to EGF and is a mitogen in rat proximal tubule. Am J Physiol. 1995;269(6 Pt 2): F806-F816.

4. O’Donnell VB, Maskrey B, Taylor GW. Eicosanoids: generation and detection in mammalian cells. Methods Mol Biol. 2009;462:5-23.

5. Imig JD. Eicosanoid regulation of the renal vasculature. Am J Physiol Renal Physiol. 2000;279(6):F965-F981.

6. Chatziantoniou C, Arendshorst WJ. Renal vascular reactivity to vasodilator prostaglandins in genetically hypertensive rats. Am J Physiol. 1992;262(1 Pt 2):F124-F130.

7. Wang D, DuBois RN. Prostaglandins and cancer. Gut. 2006;55(1): $115-122$. 
8. Wang D, DuBois RN. Eicosanoids and cancer. Nat Rev Cancer. 2010;10(3):181-193.

9. Rigas B, Goldman IS, Levine L. Altered eicosanoid levels in human colon cancer. J Lab Clin Med. 1993;122(5):518-523.

10. Wang D, Dubois RN. Cyclooxygenase-2: a potential target in breast cancer. Semin Oncol. 2004;31(1 Suppl 3):64-73.

11. McLemore TL, Hubbard WC, Litterst CL, et al. Profiles of prostaglandin biosynthesis in normal lung and tumor tissue from lung cancer patients. Cancer Res. 1988;48(11):3140-3147.

12. Sorokin A. Cyclooxygenase-2: potential role in regulation of drug efflux and multidrug resistance phenotype. Curr Pharm Des. 2004;10(6): 647-657.

13. Patel VA, Dunn MJ, Sorokin A. Regulation of MDR-1 (P-glycoprotein) by cyclooxygenase-2. J Biol Chem. 2002;277(41):38915-38920.

14. Myung SJ, Rerko RM, Yan M, et al. 15-hydroxyprostaglandin dehydrogenase is an in vivo suppressor of colon tumorigenesis. Proc Natl Acad Sci U S A. 2006;103(32):12098-12102.

15. Nakanishi M, Montrose DC, Clark P, et al. Genetic deletion of mPGES-1 suppresses intestinal tumorigenesis. Cancer Res. 2008;68(9): 3251-3259.

16. Buchanan FG, Wang D, Bargiacchi F, DuBois RN. Prostaglandin E2 regulates cell migration via the intracellular activation of the epidermal growth factor receptor. J Biol Chem. 2003;278(37):35451-35457.

17. Pai R, Soreghan B, Szabo IL, Pavelka M, Baatar D, Tarnawski AS. Prostaglandin E2 transactivates EGF receptor: a novel mechanism for promoting colon cancer growth and gastrointestinal hypertrophy. Nat Med. 2002;8(3):289-293.

18. Sheng H, Shao J, Washington MK, DuBois RN. Prostaglandin $\mathrm{E} 2$ increases growth and motility of colorectal carcinoma cells. J Biol Chem. 2001;276(21):18075-18081.

19. Wang D, Wang H, Shi Q, et al. Prostaglandin E(2) promotes colorectal adenoma growth via transactivation of the nuclear peroxisome proliferator-activated receptor delta. Cancer Cell. 2004;6(3): 285-295.

20. Sheng H, Shao J, Morrow JD, Beauchamp RD, DuBois RN. Modulation of apoptosis and $\mathrm{Bcl}-2$ expression by prostaglandin $\mathrm{E} 2$ in human colon cancer cells. Cancer Res. 1998;58(2):362-366.

21. Poligone B, Baldwin AS. Positive and negative regulation of NF-kappaB by COX-2: roles of different prostaglandins. J Biol Chem. 2001;276(42) 38658-38664.

22. Fosslien E. Review: molecular pathology of cyclooxygenase-2 in cancer-induced angiogenesis. Ann Clin Lab Sci. 2001;31(4):325-348.

23. Gately $\mathrm{S}$. The contributions of cyclooxygenase- 2 to tumor angiogenesis. Cancer Metastasis Rev. 2000;19(1-2):19-27.

24. Takaku K, Sonoshita M, Sasaki N, et al. Suppression of intestinal polyposis in Apc(delta 716) knockout mice by an additional mutation in the cytosolic phospholipase A(2) gene. J Biol Chem. 2000; 275(44):34013-34016.

25. Trompezinski S, Pernet I, Schmitt D, Viac J. UV radiation and prostaglandin E2 up-regulate vascular endothelial growth factor (VEGF) in cultured human fibroblasts. Inflamm Res. 2001;50(8):422-427.

26. Pai R, Szabo IL, Soreghan BA, Atay S, Kawanaka H, Tarnawski AS. PGE(2) stimulates VEGF expression in endothelial cells via ERK2/ JNK1 signaling pathways. Biochem Biophys Res Commun. 2001;286(5): 923-928.

27. Pradono $\mathrm{P}$, Tazawa R, Maemondo M, et al. Gene transfer of thromboxane A(2) synthase and prostaglandin I(2) synthase antithetically altered tumor angiogenesis and tumor growth. Cancer Res. 2002;62(1):63-66.

28. Il Lee S, Zuo X, Shureiqi I. 15-Lipoxygenase-1 as a tumor suppressor gene in colon cancer: is the verdict in? Cancer Metastasis Rev. 2011; 30(3-4):481-491.

29. Gao X, Grignon DJ, Chbihi T, et al. Elevated 12-lipoxygenase mRNA expression correlates with advanced stage and poor differentiation of human prostate cancer. Urology. 1995;46(2):227-237.

30. Larré S, Tran N, Fan C, et al. PGE2 and LTB4 tissue levels in benign and cancerous prostates. Prostaglandins Other Lipid Mediat. 2008;87(1-4): $14-19$.
31. Dreyling KW, Hoppe U, Peskar BA, Morgenroth K, Kozuschek W, Peskar BM. Leukotriene synthesis by human gastrointestinal tissues. Biochim Biophys Acta. 1986;878(2):184-193.

32. Hennig R, Ding XZ, Tong WG, et al. 5-lipoxygenase and leukotriene $\mathrm{B}(4)$ receptor are expressed in human pancreatic cancers but not in pancreatic ducts in normal tissue. Am J Pathol. 2002;161(2):421-428.

33. Ihara A, Wada K, Yoneda M, Fujisawa N, Takahashi H, Nakajima A. Blockade of leukotriene B4 signaling pathway induces apoptosis and suppresses cell proliferation in colon cancer. J Pharmacol Sci. 2007; 103(1):24-32.

34. Kandouz M, Nie D, Pidgeon GP, Krishnamoorthy S, Maddipati KR, Honn KV. Platelet-type 12-lipoxygenase activates NF-kappaB in prostate cancer cells. Prostaglandins Other Lipid Mediat. 2003;71(3-4): 189-204.

35. Nie D, Krishnamoorthy S, Jin R, et al. Mechanisms regulating tumor angiogenesis by 12-lipoxygenase in prostate cancer cells. J Biol Chem. 2006;281(27):18601-18609.

36. McCabe NP, Selman SH, Jankun J. Vascular endothelial growth factor production in human prostate cancer cells is stimulated by overexpression of platelet 12-lipoxygenase. Prostate. 2006;66(7):779-787.

37. Tang DG, Grossi IM, Chen YQ, Diglio CA, Honn KV. 12(S)-HETE promotes tumor-cell adhesion by increasing surface expression of alpha $\mathrm{V}$ beta 3 integrins on endothelial cells. Int J Cancer. 1993;54(1):102-111.

38. Panigrahy D, Kaipainen A, Greene ER, Huang S. Cytochrome P450-derived eicosanoids: the neglected pathway in cancer. Cancer Metastasis Rev. 2010;29(4):723-735.

39. Roman RJ. P-450 metabolites of arachidonic acid in the control of cardiovascular function. Physiol Rev. 2002;82(1):131-185.

40. Capdevila JH, Falck JR, Harris RC. Cytochrome P450 and arachidonic acid bioactivation. Molecular and functional properties of the arachidonate monooxygenase. J Lipid Res. 2000;41(2):163-181.

41. Wang D, DuBois RN. Measurement of eicosanoids in cancer tissues. Methods Enzymol. 2007;433:27-50.

42. Powell PK, Wolf I, Jin R, Lasker JM. Metabolism of arachidonic acid to 20-hydroxy-5,8,11, 14-eicosatetraenoic acid by P450 enzymes in human liver: involvement of CYP4F2 and CYP4A11. J Pharmacol Exp Ther. 1998;285(3):1327-1336.

43. Bellamine A, Wang Y, Waterman MR, et al. Characterization of the CYP4A11 gene, a second CYP4A gene in humans. Arch Biochem Biophys. 2003;409(1):221-227.

44. Christmas P, Jones JP, Patten CJ, et al. Alternative splicing determines the function of CYP4F3 by switching substrate specificity. J Biol Chem. 2001;276(41):38166-38172.

45. Yu W, Chai H, Li Y, et al. Increased expression of CYP4Z1 promotes tumor angiogenesis and growth in human breast cancer. Toxicol Appl Pharmacol. 2012;264(1):73-83.

46. Muller DN, Schmidt C, Barbosa-Sicard E, et al. Mouse Cyp4a isoforms: enzymatic properties, gender- and strain-specific expression, and role in renal 20-hydroxyeicosatetraenoic acid formation. Biochem J. 2007;403(1):109-118.

47. Yamaguchi Y, Kirita S, Hasegawa H, et al. Contribution of CYP4A8 to the formation of 20-hydroxyeicosatetraenoic acid from arachidonic acid in rat kidney. Drug Metab Pharmacokinet. 2002;17(2):109-116.

48. Nakagawa K, Holla VR, Wei Y, et al. Salt-sensitive hypertension is associated with dysfunctional Cyp4a10 gene and kidney epithelial sodium channel. J Clin Invest. 2006;116(6):1696-1702.

49. Escalante B, Sessa WC, Falck JR, Yadagiri P, Schwartzman ML. Vasoactivity of 20-hydroxyeicosatetraenoic acid is dependent on metabolism by cyclooxygenase. J Pharmacol Exp Ther. 1989;248(1): 229-232.

50. Harder DR, Narayanan J, Gebremedhin D. Pressure-induced myogenic tone and role of 20-HETE in mediating autoregulation of cerebral blood flow. Am J Physiol Heart Circ Physiol. 2011;300(5):H1557-H1565.

51. Williams JM, Sarkis A, Lopez B, Ryan RP, Flasch AK, Roman RJ. Elevations in renal interstitial hydrostatic pressure and 20-hydroxyeicosatetraenoic acid contribute to pressure natriuresis. Hypertension. 2007;49(3):687-694. 
52. Williams JM, Murphy S, Burke M, Roman RJ. 20-hydroxyeicosatetraeonic acid: a new target for the treatment of hypertension. $J$ Cardiovasc Pharmacol. 2010;56(4):336-344.

53. Quigley R, Baum M, Reddy KM, Griener JC, Falck JR. Effects of 20-HETE and 19(S)-HETE on rabbit proximal straight tubule volume transport. Am J Physiol Renal Physiol. 2000;278(6):F949-F953.

54. Wang S, Meng F, Xu J, Gu Y. Effects of lipids on ENaC activity in cultured mouse cortical collecting duct cells. J Membr Biol. 2009;227(2):77-85.

55. Pavlov TS, Ilatovskaya DV, Levchenko V, Mattson DL, Roman RJ, Staruschenko A. Effects of cytochrome P-450 metabolites of arachidonic acid on the epithelial sodium channel (ENaC). Am J Physiol Renal Physiol. 2011;301(3):F672-F681.

56. Hoagland KM, Flasch AK, Roman RJ. Inhibitors of 20-HETE formation promote salt-sensitive hypertension in rats. Hypertension. 2003;42(4): 669-673.

57. Chen L, Ackerman R, Guo AM. 20-HETE in neovascularization. Prostaglandins Other Lipid Mediat. 2012;98(3-4):63-68.

58. Amaral SL, Maier KG, Schippers DN, Roman RJ, Greene AS. CYP4A metabolites of arachidonic acid and VEGF are mediators of skeletal muscle angiogenesis. Am J Physiol Heart Circ Physiol. 2003;284(5): H1528-H1535.

59. Rapisarda A, Melillo G. Role of the VEGF/VEGFR axis in cancer biology and therapy. Adv Cancer Res. 2012;114:237-267.

60. Ishizuka T, Cheng J, Singh H, et al. 20-hydroxyeicosatetraenoic acid stimulates nuclear factor-kappaB activation and the production of inflammatory cytokines in human endothelial cells. J Pharmacol Exp Ther. 2008;324(1):103-110.

61. Zeng Q, Han Y, Bao Y, et al. 20-HETE increases NADPH oxidasederived ROS production and stimulates the L-type $\mathrm{Ca} 2+$ channel via a PKC-dependent mechanism in cardiomyocytes. Am J Physiol Heart Circ Physiol. 2010;299(4):H1109-H1117.

62. Akbulut T, Regner KR, Roman RJ, Avner ED, Falck JR, Park F. 20-HETE activates the Raf/MEK/ERK pathway in renal epithelial cells through an EGFR- and c-Src-dependent mechanism. Am J Physiol Renal Physiol. 2009;297(3):F662-F670.

63. Alexanian A, Miller B, Roman RJ, Sorokin A. 20-HETE-producing enzymes are up-regulated in human cancers. Cancer Genomics Proteomics. 2012;9(4):163-169.

64. Lai G, Wu J, Liu X, Zhao Y. 20-HETE induces hyperglycemia through the cAMP/PKA-PhK-GP pathway. Mol Endocrinol. 2012;26(11): 1907-1916

65. Guo M, Roman RJ, Fenstermacher JD, et al. 9L gliosarcoma cell proliferation and tumor growth in rats are suppressed by N-hydroxy- $\mathrm{N}^{\prime}$ (4-butyl-2-methylphenol) formamidine (HET0016), a selective inhibitor of CYP4A. J Pharmacol Exp Ther. 2006;317(1):97-108.

66. Alexanian A, Rufanova VA, Miller B, Flasch A, Roman RJ, Sorokin A. Down-regulation of 20-HETE synthesis and signaling inhibits renal adenocarcinoma cell proliferation and tumor growth. Anticancer Res. 2009;29(10):3819-3824.

67. Miyata N, Taniguchi K, Seki T, et al. HET0016, a potent and selective inhibitor of 20-HETE synthesizing enzyme. Br J Pharmacol. 2001;133(3):325-329.

68. Sato M, Ishii T, Kobayashi-Matsunaga Y, et al. Discovery of a $\mathrm{N}^{\prime}$-hydroxyphenylformamidine derivative HET0016 as a potent and selective 20-HETE synthase inhibitor. Bioorg Med Chem Lett. 2001;11(23):2993-2995.

69. Yu M, Cambj-Sapunar L, Kehl F, et al. Effects of a 20-HETE antagonist and agonists on cerebral vascular tone. Eur J Pharmacol. 2004;486(3): 297-306.

70. Qin X, Kwansa H, Bucci E, Roman RJ, Koehler RC. Role of 20-HETE in the pial arteriolar constrictor response to decreased hematocrit after exchange transfusion of cell-free polymeric hemoglobin. $J$ Appl Physiol. 2006;100(1):336-342.

71. StecDE, Gannon KP, Beaird JS, DrummondHA. 20-hydroxyeicosatetraenoic acid (20-HETE) stimulates migration of vascular smooth muscle cells. Cell Physiol Biochem. 2007;19(1-4):121-128.
72. Tunctan B, Korkmaz B, Buharalioglu CK, et al. A 20hydroxyeicosatetraenoic acid agonist, $\mathrm{N}$-[20-hydroxyeicosa-5(Z), 14(Z)dienoyl]glycine, opposes the fall in blood pressure and vascular reactivity in endotoxin-treated rats. Shock. 2008;30(3):329-335.

73. Regner KR, Zuk A, Van Why SK, et al. Protective effect of 20-HETE analogues in experimental renal ischemia reperfusion injury. Kidney Int. 2009;75(5):511-517.

74. Park F, Sweeney WE, Jia G, Roman RJ, Avner ED. 20-HETE mediates proliferation of renal epithelial cells in polycystic kidney disease. $\mathrm{J} \mathrm{Am}$ Soc Nephrol. 2008;208(10):1929-1939.

75. Nithipatikom K, Isbell MA, See WA, Campbell WB. Elevated 12- and 20-hydroxyeicosatetraenoic acid in urine of patients with prostatic diseases. Cancer Lett. 2006;233(2):219-225.

76. Jacobs VL, Valdes PA, Hickey WF, De Leo JA. Current review of in vivo GBM rodent models: emphasis on the CNS-1 tumour model. ASN Neuro. 2011;3(3):e00063.

77. Guo M, Roman RJ, Falck JR, Edwards PA, Scicli AG. Human U251 glioma cell proliferation is suppressed by HET0016 [N-hydroxy- $\mathrm{N}^{\prime}-$ (4-butyl-2-methylphenyl)formamidine], a selective inhibitor of CYP4A. $J$ Pharmacol Exp Ther. 2005;315(2):526-533.

78. Chen P, Guo M, Wygle D, et al. Inhibitors of cytochrome P450 4A suppress angiogenic responses. Am J Pathol. 2005;166(2):615-624.

79. Guo AM, Sheng J, Scicli GM, et al. Expression of CYP4A1 in U251 human glioma cell induces hyperproliferative phenotype in vitro and rapidly growing tumors in vivo. $J$ Pharmacol Exp Ther. 2008;327(1): $10-19$.

80. Yu W, Chen L, Yang YQ, et al. Cytochrome P450 $\omega$-hydroxylase promotes angiogenesis and metastasis by upregulation of VEGF and MMP-9 in non-small cell lung cancer. Cancer Chemother Pharmacol. 2011;68(3):619-629.

81. Weiss RH, Lin PY. Kidney cancer: identification of novel targets for therapy. Kidney Int. 2006;69(2):224-232.

82. Wu CC, Liu Y, Chen J, et al. CYP4F isoform expression and 20-HETE synthesis in prostate cancer cells are regulated by androgen and contribute to growth [abstract]. Cancer Res. 2012;72(8 Suppl 1): LB-160.

83. Arun B, Goss P. The role of COX-2 inhibition in breast cancer treatment and prevention. Semin Oncol. 2004;31(2 Suppl 7):22-29.

84. Badawi AF. The role of prostaglandin synthesis in prostate cancer. $B J U$ Int. 2000;85(4):451-462.

85. Gupta RA, DuBois RN. Translational studies on Cox-2 inhibitors in the prevention and treatment of colon cancer. Ann NY Acad Sci. 2000; 910:196-204.

86. Myers CE, Ghosh J. Lipoxygenase inhibition in prostate cancer. Eur Urol. 1999;35(5-6):395-398.

87. Sorokin A. Eicosanoids and resistance of cancer cells to chemotherapeutic agents. In: Bonavida B, editor. Sensitization of Cancer Cells for Chemo/Immuno/Radio-therapy. Los Angeles, CA: Humana Press; 2008:133-156.

88. Khan M, Fraser A. Cox-2 inhibitors and the risk of cardiovascular thrombotic events. Ir Med J. 2012;105(4):119-121.

89. Garcia Rodriguez LA, Cea-Soriano L, Tacconelli S, Patrignani P. Coxibs: pharmacology, toxicity and efficacy in cancer clinical trials. Recent Results Cancer Res. 2013;191:67-93.

90. Gibson GG. Comparative aspects of the mammalian cytochrome P450 IV gene family. Xenobiotica. 1989;19(10):1123-1148.

91. McGiff JC, Carroll MA. Cytochrome P450-dependent arachidonate metabolites, renal function and blood pressure regulation. $A d v$ Prostaglandin Thromboxane Leukot Res. 1991;21B:675-682.

92. Miyata N, Roman RJ. Role of 20-hydroxyeicosatetraenoic acid (20-HETE) in vascular system. J Smooth Muscle Res. 2005;41(4): $175-193$. 
OncoTargets and Therapy

\section{Publish your work in this journal}

OncoTargets and Therapy is an international, peer-reviewed, open access journal focusing on the pathological basis of all cancers, potential targets for therapy and treatment protocols employed to improve the management of cancer patients. The journal also focuses on the impact of management programs and new therapeutic agents and protocols on

patient perspectives such as quality of life, adherence and satisfaction. The manuscript management system is completely online and includes a very quick and fair peer-review system, which is all easy to use. Visit http://www.dovepress.com/testimonials.php to read real quotes from published authors.

Submit your manuscript here: http://www.dovepress.com/oncotargets-and-therapy-journal 